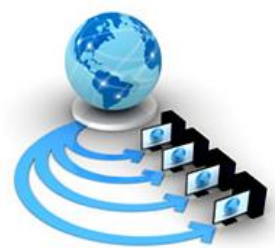

Volume 9, No. 3, May-June 2018

International Journal of Advanced Research in Computer Science

RESEARCH PAPER

\title{
STATE OF MOBILE CLOUD COMPUTING WITHIN GOVERNMENT SECTOR
}

\author{
Amanpreet Kaur \\ Post Graduate Diploma in IT, \\ MCA(Punjabi University, Patiala),India \\ Postgraduate Diploma in IT(EIT,Auckland,New Zealand)
}

\begin{abstract}
Today many government organizations are exploring the benefits of cloud computing .With the help of the new technology government is providing better and efficient services to the citizens. In addition, to the cloud computing government is also started using mobile cloud in order to make the most from cloud computing. Mobile cloud computing is a service in which benefits of both cloud computing and mobile go hand in hand in order to provide better services.

This paper explore current state of mobile cloud computing in different government organizations .It will also identify the benefits and challenges faced by the organizations while using Mobile cloud computing.
\end{abstract}

Keywords: Cloud computing, mobile cloud, challenges, benefits, current state

\section{INTRODUCTION}

Cloud computing is an approach that is formed from the aggregation and development of different technologies such as distributed, grid and parallel computing. Its main focus is to provide various services such as communication, storage resources in a secured environment virtually with the help of Internet which serves as a platform [1].

Mobile Cloud Computing is a model in which all the functions such as processing and storage are done in the cloud and mobile devices act as a platform for the presentation of the data. The basic components of the mobile cloud computing model are a working phone or a tablet, a reliable Internet connection and ability to run a browser or any other application that can be used for viewing of the content. With the growth in the mobile computing sector, each mobile is capable of transmitting and sharing the extensive amount of data among the mobile users [2].Mobile cloud computing is defined as the combination of two technologies mobile computing and cloud computing in this environment the user or a client can use the cloud computing benefits and services within the mobile ecosystem [3].

With the help of cloud computing a user who uses cloud services spend less time in managing the IT resources that are complex in nature instead user spends more time in investing in its natural work [4]. According to National Institute of Standards and Technology (NIST), there are five essential characteristics of the cloud computing that are demand service, resource pooling, service, rapid elasticity(services that can be updated, accessible and improved at any time ) and broad network access [5].

\section{USE OF MOBILE CLOUD WITHIN GOVERNMENT}

Government always experience the new and increasing pressures on their financial and human resources which occur due to changing demands and growing population
[6].To meet the rising expectations of citizens for better and improved information mobile internet and its related technology is playing the advanced role for delivery of information to the users which in turn leads to the development of Mobile government[7].The government's digital background has been transforming at a constant phase to show the changes that governments are trying to find for innovating themselves to digitization while experiencing social, economic, political and other external pressures.The policymakers, government officials, and higher authorities are preparing to make and implement these digital government decisions [8]. In the government sector, cloud computing provides an operational model that can collaborate the distant remote centers into a common infrastructure whereas it also provides one single gateway to government-related services and data [9].But in the Arab countries cloud computing applications are still in their developing state and are usually provided by the local operators [10].

\section{CURRENT STATE OF MOBILE CLOUD IN GOVERNMENT}

As there is lack of standard policies and regulations many government agencies are safeguarding themselves while implementing cloud fully. To test the applicability of mobile phones within the government agencies various pilot programs have been implemented. For instance, C2 technologies of Vienna has developed an iPhone application that was released by Army so as to teach the Army Patriot Missile Crews about the use of Patriot system.This application allows the soldier to train anytime and anywhere.It also helps the soldiers to access the critical information in the respective field [11].

Scenarios where mobile cloud computing is helping citizens to gain a better experience with government:

a) Johannesburg Roads Agency (JRA): The JRA sensed that there is the opportunity to improve its various operations related to the maintenance of 
bridges, roads and other infrastructure related to transportation. They also sensed that citizen satisfaction can also be improved as they understood that citizens can be their eyes and ears while spotting the issues that need to be fixed. So JRA introduced the "Find and Fix" mobile application on the Microsoft cloud platform. This mobile app allows the citizens to report any issue with the help of their smartphone.The advantage of this application was that the issue resolving time which was earlier from 32 days reduced to less than a day which in turn changed the public perceptions about the government efficiency [6].

b) Holland Kroon: It is a municipality organization in the Netherlands. They have thought about that how the different employees working in the organization wants to work whether from home, office or from any other location. They have used a digital solution that helps them to be in touch, share and meet and do their work irrespective of their location.The employees use their laptops, tablets or smartphones to work from wherever they want to.This resulted in improving data-driven decision making and having a more mobile workforce that can deliver better services to its citizens [6].

c) Cardinia Shir Council: In Melbourne, the council is using Skype for business to assist people in becoming the modern activity workforce.The employees can easily connect and share their views on the project they are working on irrespective of their location. This resulted in increasing the productivity and $15 \%$ of the council building is not needed which in turn reduced the further expenses[6].

d) Adoption of eSign Service Program in Hawaii: In Hawaii to be responsive to citizens and to be held accountable government departments have to manage a lot of paper trails and document approvals.So to cut the cost and work efficiently and effectively the paperless initiative was needed.So the introduction of eSign Services from Adobe Sign came as a solution that helps various employees, government officials and higher authorities to sign any document electronically.So with the help of Adobe Sign and Adobe Creative Cloud for enterprise the State of Hawaii can deliver effectively the needed applications on the mobiles, laptops or tablets of the staff.As stated by the CIO of Hawaii the Adobe Sign in Adobe Document Cloud offers flexibility to encourage the adoption of paperless workflows for efficient working inside and outside government [12].

e) NASA Nebula 5: With the help of open source community cloud "Nebula". The researchers can easily access IT services and share a large amount of data. However, it would take researchers months to configure IT resources and use them significantly if it would not have been a cloud.
Nebula also promotes rapid software development and code reuse [4].

4. Benefits and challenges faced by Government agencies while using mobile cloud

According to the Report by Digital Government Strategy Milestone 5.4, there is a number of challenges faced by the government agencies while using a different type of mobile applications whether it is the cloud applications or commercial mobile applications [13].

a) It is a complex task to control and regulate the access of different mobile applications on the mobile devices provided by the government.

b) As there is a number of mobile operating systems, device models and mobile applications are available so security becomes the major concern.

c) For each application high level of government review and negotiation is required.

In the current scenario development of cloud applications on the mobile devices is a complex process due to various reasons such as limited computing resources and better web browsers. Also, the main issues that are to be taken into account for the mobile cloud are network bandwidth, availability, and security. For instance, Google's open source mobile phone is offering many enterprise security policies that are necessary for mobile cloud computing within the organization [14].There should be standards for security and privacy so as to keep the data of citizens or the government confidential. As most of the frameworks overlooked the security issue but the framework to be used in government sector should provide the data privacy, data storage at high levels [15].In addition to security, privacy and data storage there are other problems too such as if the mobile application requires a lot of battery then it will be hard to use that application in a mobile environment [16].Although with mobile cloud computing there can be a number of benefits such as flexibility, real-time data availability and supports multiple platforms [17].

\section{RECOMMENDATIONS AND FUTURE WORK}

In Mobile Cloud Computing if the mobile device of a government official is lost or stolen then there is a chance that the data in the device can go in the wrong hands that can be hazardous. So an appropriate framework for the data security during mobile cloud computing should be followed. In mobile cloud computing the benefits of the mobile environment are integrated with the cloud computing environment and various challenges related to performance and security are also surpassed [18]. The future of mobile cloud computing will completely change the way of communication between the government and the people who are interacting with it. It will also improve the business of those IT companies that provide such mobile applications and cloud platforms [19].Mobile government is in very starting stages and only a few government agencies have begun to implement full mobile government services. Government agencies foresee the delivery of services to citizens in an integrated manner and still the use of mobile devices and tools in an instant challenge [20].The main aim of implementing the Mobile cloud computing is to gain the benefits of cloud computing and mobile techniques. 
Although, dynamic networking environment results in deployment of services in more complicated way [21].

\section{CONCLUSION}

The various challenges such as security and privacy, availability of content at all times, bandwidth are some of the issues that require constant monitoring. Although citizens always demand the best service from the government so it always been a hard to make a pace to understand and cope with changing demands of the growing population. Whereas, there are applications available that are helping citizens to connect more effectively and efficiently with the government such as Find and fix provided by Johannesburg Road Agency.However, the government still need more time to gain the trust of citizens. However, adoption of mobile cloud in the government sector will still take more time due to different reasons.

\section{REFERENCES:}

[1] S. Hashemi, K. Monfaredi, and M. Masdari, "Using cloud computing for e-government: Challenges and benefits," Int. J. Comput. Inf. Sci. Eng., vol. 7, no. 9, pp. 579-586, 2013.

[2] B. Sosinsky, Cloud computing bible. 2011, Wiley Publishing, Inc. https://doi.org/10.1002/9780470940105.

[3] S. Prasad, S. K. Peddoju, and D. Ghosh, "AgroMobile: A Cloud - Based Framework for Agriculturists on Mobile Platform,” Int. J. Adv. Sci. Technol., vol. 59, pp. 41-52, 2013.

[4] V. Kundra, "Federal cloud computing strategy," 2011, Retrieved from https://www.dhs.gov/sites/default/files/publications/digital -strategy/federal-cloud-computing-strategy.pdf.

[5] P. Mell and T. Grance, "The NIST definition of cloud computing," NISTSpecial Publication. p. 7, 2011. https://doi.org/10.1136/emj.2010.096966.

[6] "The digital transformation of government." 2015, Retrieved from https://info.microsoft.com/DigitalTransformationofGovern ment-ThankYou.html?aliId=455159757.

[7] Konstantin, Aleksandar, Aleksandra, Bozidaar, and Branislav, "E-govenrment model based on mobile cloud computing," Metal. Int., vol. XVII, no. 9, pp. 174-179, 2012.

[8] T. Janowski, "Digital government evolution: From transformation to contextualization," Gov. Inf. Q., vol. 32, no. 3, pp. 221-236, 2015.

[9] D. Zissis and D. Lekkas, "Securing e-government and evoting with an open cloud computing architecture," Gov. Inf. Q., vol. 28, no. 2, pp. 239-251, 2011.

[10] H. Tadili and A. Semma, "How governments can benefit from cloud computing," Int. J. Comput. Sci. Issues, vol. 12, no. 5, pp. 170-174, 2015.

[11] D. Quick, "U.S army takes delivery of iphone app for patriot missile training," 2012. [Online]. Available: $\mathrm{http}: / /$ newatlas.com/patriot-missile-training-iphoneapp/17941/.

[12] "Increasing government efficiency in the aloha state," $2016 . \quad$ [Online]. Available: http://wwwimages.adobe.com/content/dam/acom/en/mark eting-cloud/customer-success/pdf/54658.en.amcgov.customer-success.state-of-hawaii.pdf.

[13] "Adoption of commercial mobile applications within the federal government," 2013, Retrieved from https://s3.amazonaws.com/sitesusa/wpcontent/uploads/sites/1151/downloads/2013/05/Commerci al-Mobile-Application-Adoption-DGS-Milestone-5.4.pdf.

[14] T. J. Kwasniewski and E. Puig, "Cloud computing in the government," 2011, Journal of Chemical Information and Modeling.

https://doi.org/10.1017/CBO9781107415324.004

[15] A. C. Donald, S. A. Oli, and D. L. Arockiam, "Mobile cloud security issues and challenges: A perspective," Int. J. Eng. Innov. Technol., vol. 3, no. 1, pp. 401-406, 2013.

[16] W. Song and X. Su, "Review of mobile cloud computing," pp. $1-4$, 2011 . https://doi.org/10.1109/ICCSN.2011.6014374

[17] "Mobile cloud computing," 2014. [Online]. Available: https://www.getcloudservices.com/blog/mobile-cloudcomputing-pros-and-cons/.

[18] M. R. Prasad, J. Gyani, and P. R. . Murti, "Mobile cloud computing: Implications and challenges," J. Comput. Inf. Sci. Eng., vol. 2, no. 7, pp. 7-16, 2012.

[19] D. C. Wyld, "The cloudy future of government IT: Cloud computing and the public sector around the world," Int. J. Web Semant. Technol., vol. 1, no. 1, pp. 1-20, 2010.

[20] S. Khanesha and D. A. Jani, "Mobile augmented integrated framework for citizen centric E-governance services-MAIFCCES,” Int. J. Inf. Eng. Electron. Bus., vol. 8, no. 3, pp. 47-56, 2016.

[21] K. Gai, M. Qiu, H. Zhao, L. Tao, and Z. Zong, "Dynamic energy-aware cloudlet-based mobile cloud computing model for green computing," J. Netw. Comput. Appl., vol. 59, pp. 46-54, 2016. 